LCRL- JC-112023

PREPRINT

\title{
High Power, Electron-Beam Induced Switching in Diamond
}

R. D. Scarpetti, W. W. Hofer, D. R. Kania,

Lawrence Livermore National Laboratory

K. H. Schoenbach, R. P. Joshi, C. Molina,

R. P. Brinkmann, Old Dominion University

This paper was prepared for submittal to: Conference Proceedings of the 9th IEEE Pulsed

Power Conference, Albuquerque, New Mexico June 21-23, 1993

July 1993

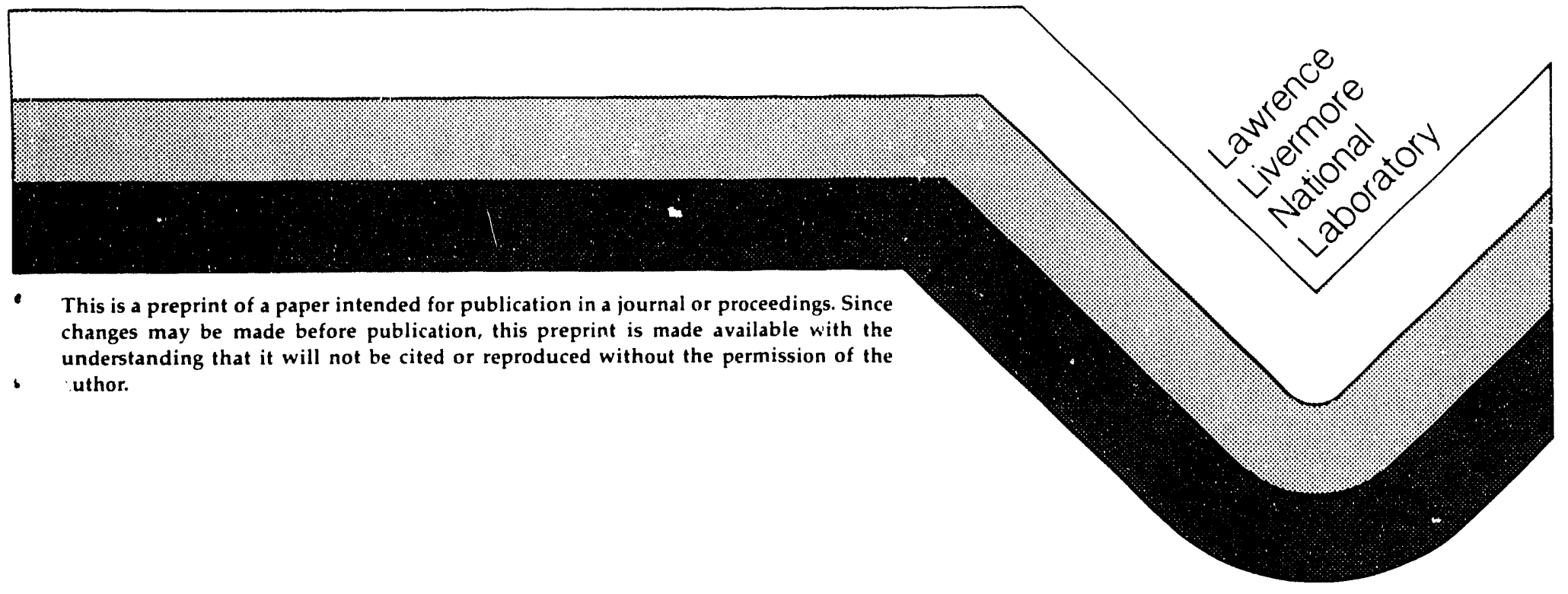

Hing

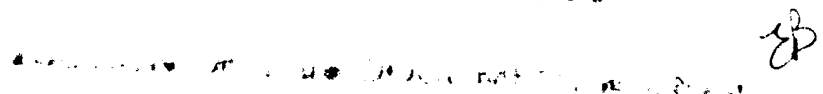




\section{DISCLAIMER}

This document was prepared as an account of work sponsored by an agency of the United States Government. Neither the United States Government nor the University of California nor any of their employees, makes any warranty, express or implied, or assumes any legal liability or responsibility for the accuracy, completeness, or usefulness of any information, apparatus, product, or process disclosed, or represents that its use would not infringe privately owned rights. Reference herein to any specific commercial products, process, or service by trade name, trademark, manufacturer, or otherwise, does not necessarily constitute or imply its endorsement, recommendation, or favoring by the United States Government or the University of California. The views and opinions of authors expressed herein do not necessarily state or reflect those of the United States Government or the University of California, and shall not be used for advertising or product endorsement purposes. 


\title{
HIGH POWER, ELECTRON-BEAM INDUCED SWITCHING IN DIAMOND*
}

\author{
R. D. Scarpetti, W. W. Hofer, D. R. Kania \\ Lawrence Livermore National Laboratory \\ P. O. Box 808 \\ Livermore, California
K. H. Schoenbach, R. P. Joshi, C. Molina, R. P. Brinkmann
Old Dominion University
Norfolk, Virginia

\begin{abstract}
We are developing a high voltage, high average power, electron-beam controlled diamond switch that could significantly impact high power solid-state electronics in industrial and defense applications.

An electron-beam controlled thin-film diamond could switch well over $100 \mathrm{~kW}$ average power at $\mathrm{MHz}$ frequencies, greater than $5 \mathrm{kV}$, and with high efficiency. This performance is due to the excellent thermal and electronic properties of diamond, the high efficiency achieved with electron beam control, and the demonstrated effectiveness of microchannel cooling.

Our electron beam penetration depth measurements agree with our Monte-Carlo calculations. We have not observed electron beam damage in diamond for beam energies up to $150 \mathrm{keV}$.

In this paper we describe our experimental and calculational results and research objer..ves.
\end{abstract}

\section{Background}

Diamond has many properties which make it ideal for high average power, high voltage, high frequency solid state switching. Diamond has a dielectric strength of $1-10 \mathrm{MV} / \mathrm{cm}^{1}$ which is greater than an order of magnitude that ${ }^{f} \mathrm{Si}$ or GaAs, and four times that of SiC. Diamond also has the highest thermal conductivity of any solid at room temperature, up to 20 W/cm-K which is over ten times that of Si and GaAs and five times that of SiC. Diamond's high electron and hole mobility $\left(>1000 \mathrm{~cm}^{2} / \mathrm{V}\right.$-sec) allow for operating at $\mathrm{MHz}$ frequencies. The $5.47 \mathrm{eV}$ band gap results in lower dark current, higher temperature operation and hardness to radiation as compared to $\mathrm{Si}$ and $\mathrm{GaAs}$ semiconductor devices. However, this wide band gap makes it difficult to ionize using lasers. UV lasers are inefficient and expensive, while lower frequency lasers couple poorly to the high absorption length of diamond. One very efficient method of generating charge carriers in wide band gap materials such as diamond is an electron beam. Advantages of electron beam activation are broad energy ranges and easily tailored energy waveforms, high wall plug efficiencies, lower costs and higher sustained intensities than lasers. Up until now, interest in diamond devices has been limited because of its high cost and the limited supply of high purity material. However, recent advances in processing technology and the successful growth of high quality artificial diamond using vapor phase deposition, are resulting in purer materials with less defects and, potentially, at greatly reduced cost. The result is a viable material for high power solid state switching in support of the power electronics industry as well as for military applications. LLNL and Old Dominion University have begun to address electron penetration range in diamond, bulk breakdown voltage, the role of crystal defects, the effects of contacts on charge injection and dark current ${ }^{2}$, and the development of a theoretical and modeling base. Ail of which are necessary to realize the potential of electron beam controlled diamond devices as high average power solid state switches.

\section{Switch Operation}

There are three modes of operation based on incident electron beam energy and type of contacts used:

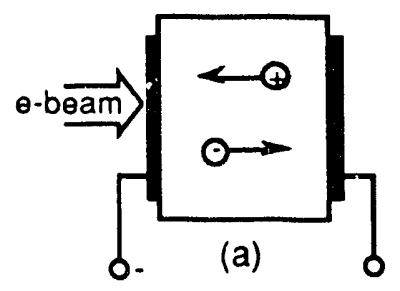

Blocking Contacts Diamond Fully Ionized
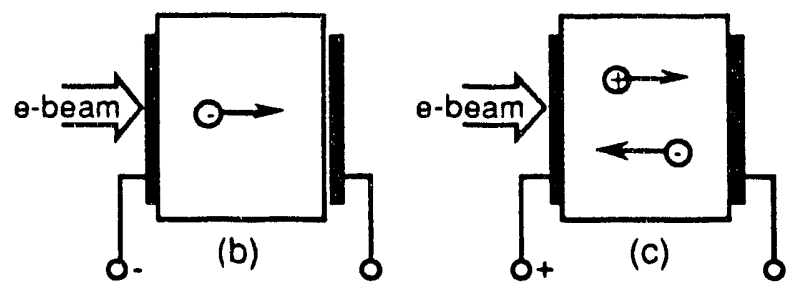

\section{Electron Injecting Contacts Diamond} Partially lonized Different Bias

Figure 1: Diamond switch operating characteristics are based on electron penetration depth and type of contact.

In the first mode, blocking contacts are used and the 
electron range equals the switch thickness. In this configuration (see figure 1a), the electron beam provides the only source of charge carriers through electron beam ionization. Since the electron hole pairs are generated simultaneously throughout the entire region, the turnon time is determined by the trap filling time in the diamond which is related to the electron beam current and can be extremely fast. Blocking contacts are used to prevent charge carrier injection through the contacts and allow for the full use of the dielectric strength of the diamond. Experimental results shown in figure 2, show annealed aluminum acts as a good blocking contact with applied electric fields of $340 \mathrm{kV} / \mathrm{cm}$ across the diamond before the onset of dark current, while the use of annealed aluminum contacts results in high dark currents at electric fields of $50 \mathrm{kV} / \mathrm{cm}$.

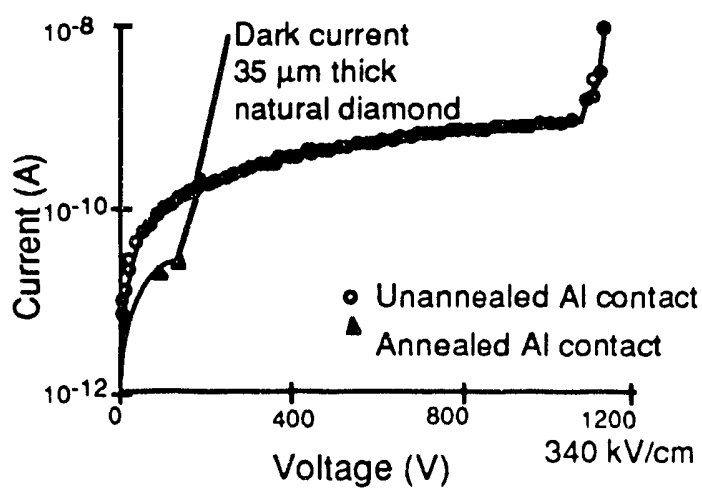

Figure 2: Unannealed aluminum acts as a blocking contact - significantly increasing the switch holdoff voltage.

The current gain of such a device is determined by the ratio of primary electron energy and the mean ionization energy for diamond, which is approximately $15 \mathrm{eV}$. Therefore, a single $150 \mathrm{keV}$ electron will generate 10,000 electron-hole pairs. Upon termination of the electron beam, the switch opens in a time determined by either the carrier lifetime or carrier sweep time, whichever is shorter. A practical limit for switch thickness and therefore holdoff voltage is determined by the maximum electron energy that can impinge on the diamond and not damage the crystal structure. For diamond this is between 150 and $200 \mathrm{keV}$ which relates to the electron range in diamond of 40 to $50 \mu \mathrm{m}$. Diamond film thickness on this order can support switch voltages of approximately $5 \mathrm{kV}$. A concept for a compact e-beam controlled diamond switch projected to operate at average powers of 100's of $\mathrm{kW}$, voltages of $5 \mathrm{kV}$ and switching frequencies of $>10 \mathrm{MHz}$ is shown in figure 3. Switching speed is estimated in nanoseconds with an overall expected efficiency of $>95 \%$. This switch concept utilizes thin film diamond with its high thermal conductivity to be able to handle the high average powers. Microchannel cooling ${ }^{3}$, which is being developed at LLNL, allows for a power dissipation of up to $70 \mathrm{~W} / \mathrm{cm}^{2}-\mathrm{C}^{\circ}$.

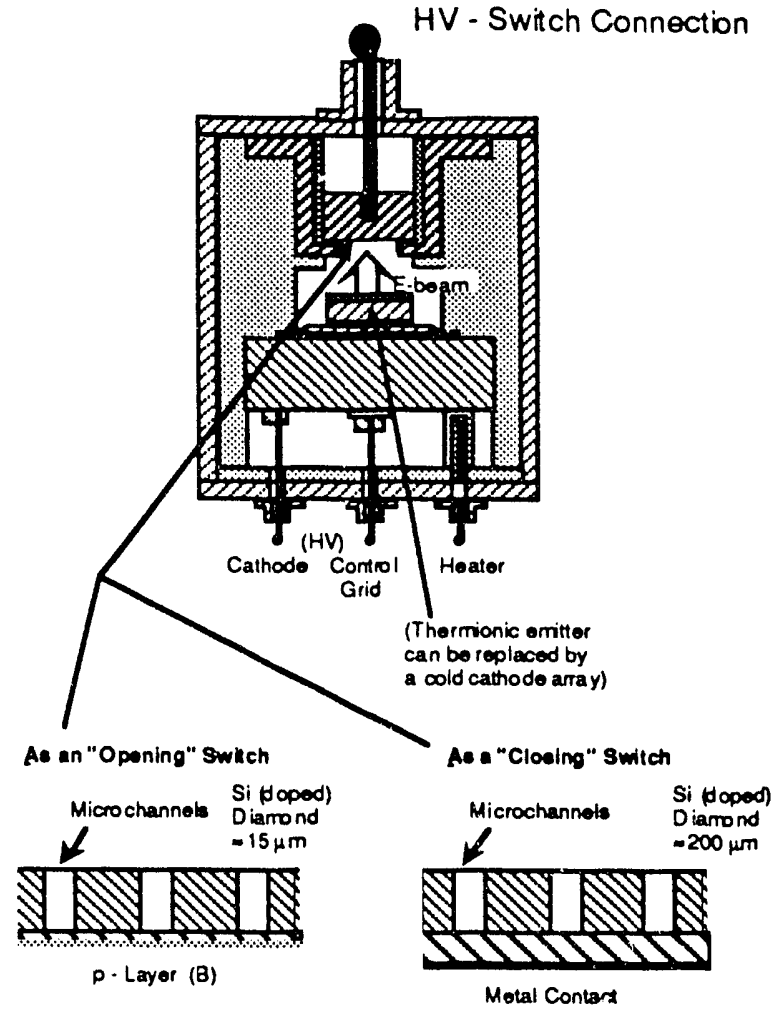

Figure 3: E-beam controlled diamond can be used as an "Opening" or "Closing" switch.

In the second mode, the contact allows for electron injection at the cathode. In this configuration the electron beam energy is lowered such that the electrons penetrate and ionize only a fraction of the switch volume in the immediate vicinity of the cathode (see figure $1 \mathrm{~b}$ ). The switch operates space charge limited with a current, $J_{s}$, which is dependent upon the switch voltage given by:

$$
\mathrm{J}_{\mathrm{s}}=\varepsilon_{\mathrm{r}} \varepsilon_{\mathrm{o}} \mu_{\mathrm{n}}\left(\mathrm{V}^{2} / \mathrm{d}^{3}\right)
$$

where $\varepsilon_{\mathrm{r}}$ and $\varepsilon_{\mathrm{o}}$ are the relative and absolute dielectric constants, $\mu_{n}$ is the electron mobility, $V$ is the applied voltage, and $d$ is the thickness of the diamond. Typical current gains for a switch of this type is $10^{4}$. The advantage of a switch operating in a single injection mode is a lower beam energy and therefore a simpler system, iowever, the tradeoff is possible switch jitter due to establishment of the drift current in the base region of the switch.

In the third mode, the switch is operated in the double injection mode, that is, both of the contacts are charge injecting. Double injection allows for higher current and power gains over the single injection mode. Here the switch is forward biased rather than reversed biased (see figure 1c). The contact opposite the electron beam irradiated face acts as an electron injector, while the electron beam generates electron-hole pairs close to the 
irradiated contact, and serves as a hole emitter. The resulting current is given by:

$$
J_{d}=\varepsilon_{r} \varepsilon_{o} \mu_{n} \mu_{p} \tau\left(V^{3} / d^{5}\right)
$$

where $\mu_{n}$ and $\mu_{p}$ are the electron and hole mobilities and $\tau$ is the charge carrier decay time.

Assuming $10 \mu \mathrm{m}$ thick diamond, a forward voltage of 25 volts, electron and hole mobilities of $1000 \mathrm{~cm}^{2} / \mathrm{V}$. $\mathrm{sec}$, a carrier decay time of $1 \mathrm{~ns}$, and a relative dielectric constant of 5.7, the calculated current density, from equation 2 , is $7.88 \mathrm{kA} / \mathrm{cm}^{2}$. As will be discussed shortly, current densities of this order were gotten using natural diamond having a thickness of five times the value used above. This is possibly due to the fact that after trap filling occurs, the carrier decay time vastly increases (due to the removal of one loss mechanism: trapping).

Experimental results using blocking contacts, single carrier injection, and double injection are shown in fig $4 a, b, c$. The results to note are:

1) Switching using blocking contacts results in a current that is approximately independent on voltage. This is expected since the carrier generation is controlled by the incident electron beam and not the voltage across the switch.

2) For single charge injection, a quadratic dependence on voltage, as described in equation 1 , is seen. The increased current with increasing electron beam energy is likely due to the deeper penetration of the electrons into the bulk diamond, and consequently, the shortening of the effective gap length, $d$.

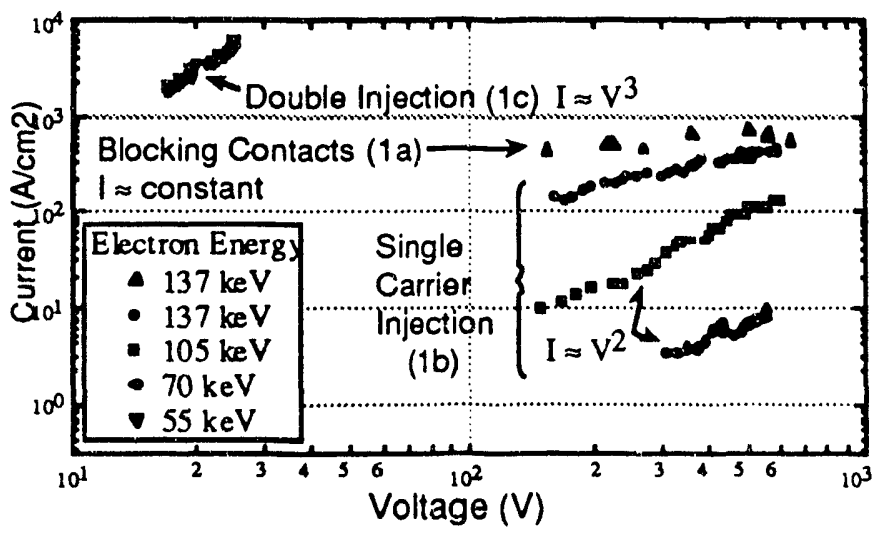

Figure 4a: Blocking, single and double charge injecting contacts exhibit expected voltage dependencies ( $50 \mu \mathrm{m}$ thick natural diamond).

3) For double charge injection, a cubic dependence upon voltage is seen and agrees nicely with equation 2 .

These results are better seen in the expanded plot in figure $4 \mathrm{~b}$. Current gains of $10^{6}$ have been obtained using $50 \mu \mathrm{m}$ thick diamond and a $55 \mathrm{keV}$ e-beam having a current density of $6 \mathrm{~mA} / \mathrm{cm}^{2}$. The switch passed a current density of $2.5 \mathrm{kA} / \mathrm{cm}^{2}$ and had a forward voltage drop of 18-25 volts. Voltage and current waveforms for a case with similar parameters is shown in figure $4 c$.

Double Injection Diamond Switching

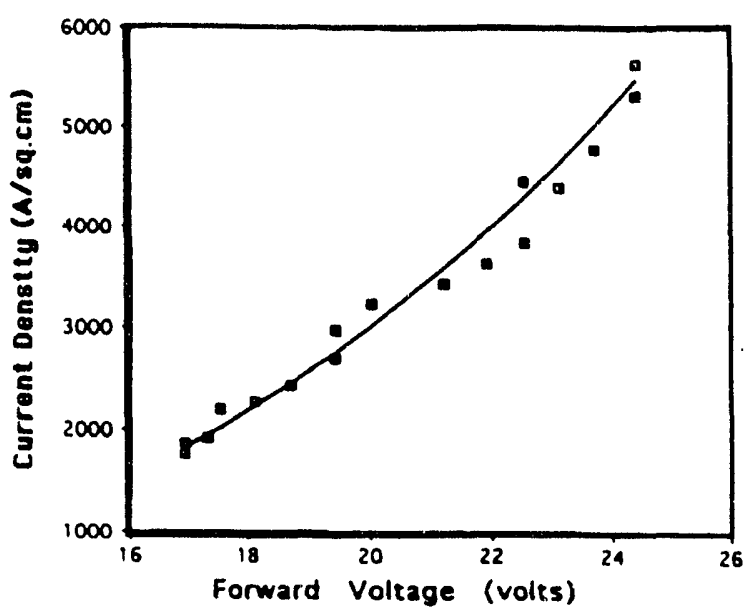

$\begin{array}{ll}\text { Diamond film: } & 50 \mu \mathrm{m} \\ \text { Contacts: } & \text { annealed Al } \\ \text { E-Beam energy: } & 55 \mathrm{keV} \\ \text { E-Beam current: } & 6 \mathrm{mAV} \mathrm{cm}^{2} \\ \text { Penetration depth: } & 10-15 \mu \mathrm{m} \\ \text { Hold-off voltage: } & >1 \mathrm{kV} \\ \text { Forwand Voltage: } & 18-25 \mathrm{~V} \\ \text { Current densities: } & 2-5 \mathrm{kAV} \mathrm{cm}^{2}\end{array}$

Figure 4b: Experiments utilizing double injection have produced current gains of $10^{6}$.

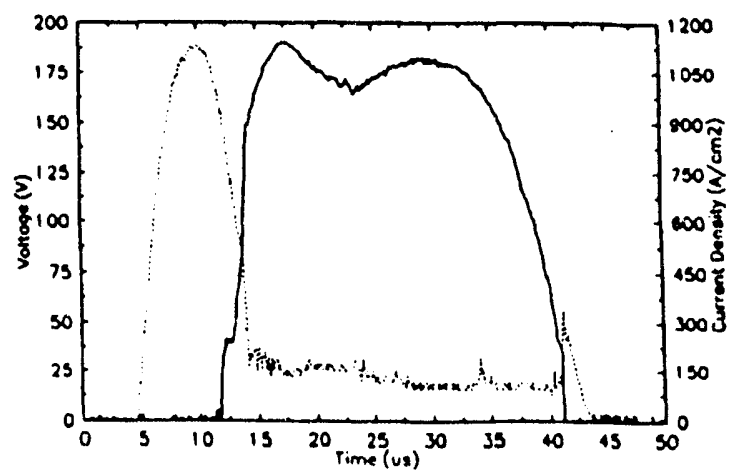

Figure 4c: Voltage and current waveforms utilizing double charge injection.

\section{Penetration of electrons and the generation of free carriers in diamond:}

In order to determine the electron distribution and the spatially dependent source functions that result in the induced conductivity in the diamond films, electron beam penetration as a function of electron incident energy was experimentally studied and compared to 
numerical Monte Carlo simulations. The two are in good agreement and the results, along with calculated carrier-generation profiles within the bulk diamond as a function of incruent elzstron energies. are discussed in detail by Joshi, et al ${ }^{4}$. The experimental setup cnnsisted of a diode having a thermionic cathode which was powered by a discrete element $40 \mathrm{kV}$ PFN which outpus into a 1:11 step up transformer. The output voltage pulse at the diode was variable from 100 to 190 $\mathrm{keV}$ and from 1 to $15 \mu \mathrm{s}$ in pulse length at current densities of up to $35 \mathrm{~mA} / \mathrm{cm}^{2}$. The emitted electron beam then passed through a $25 \mu \mathrm{m}$ titanium foil and into a $35 \mu \mathrm{m}$ thick (type II-a) diamond sample. The electrons emarging from the diamond were collected in a graphite Faraday cup. As discussed by Joshi, et al, the total collected current is a direct measure of the fraction of electrons transmitted, wh:ch relates to the electron energy loss proresses and the stopping power in diamond. The resulting energy loss and diffusion of the initially monochromatic electron beam after passing through the anode has been taken into account. The experimental and theoretical results of the transmitted fraction vs. incident electron energy are shown in figure 5 and are in very good agreement with each other. With the confidence that the Monte Carlo simulation is accurate, free charge carrier profiles throughout the diamond can be determined.

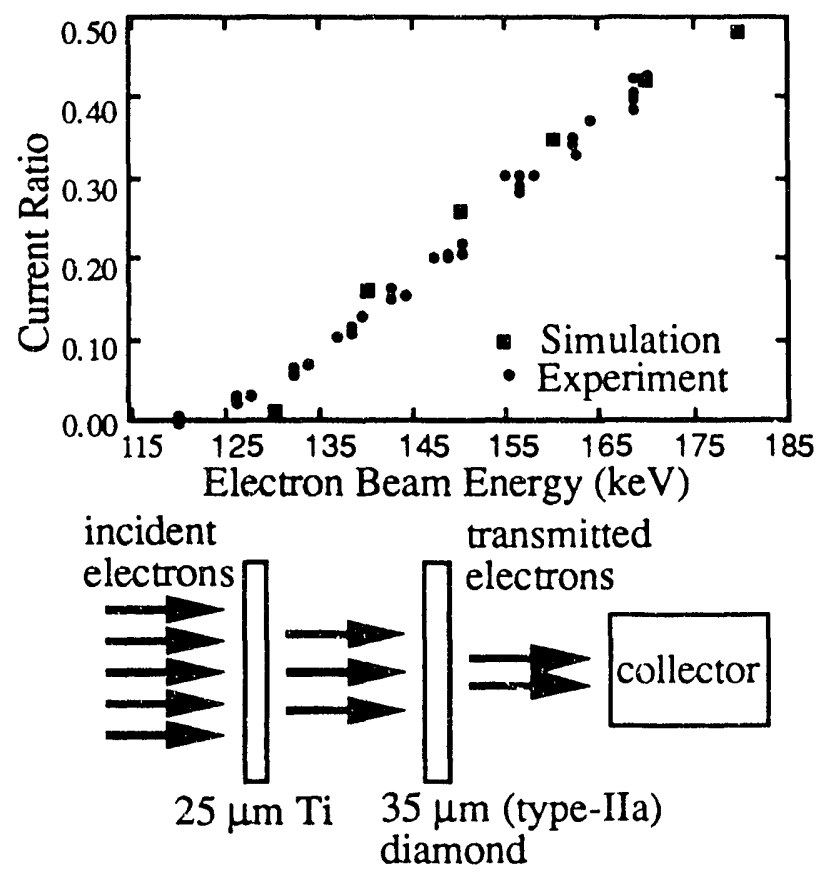

Figure 5: Electron fraction transmitted to collector.

This information is important for efficient switch design since it relates to the drift and diffusive flow of charge within the diamond. Results from the Monte Carlo simulations relating to profiles of excess carrier generation in diamond are shown in figure 6 for an electron energy of $135 \mathrm{keV}$.

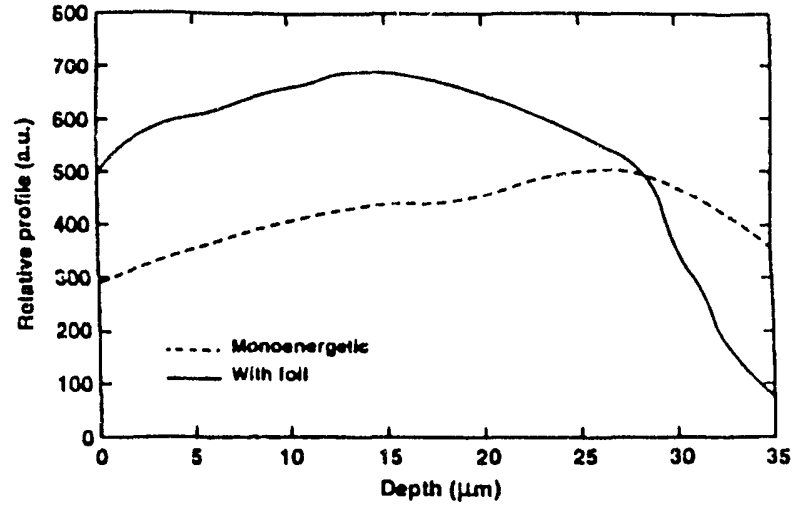

Figure 6: Profiles of carrier generation in $35 \mu \mathrm{m}$ thick diamond.

\section{Conclusions}

Diamond has many properties which make it ideal for high average power, high voltage, high frequency solid state switching. The type of contact used, the biasing and the electron beam energy all determine the operating parameters of the switch. Results of experiments using blocking and charge injecting contacts agree well with theory. Electron beam penetration and the generation of charge carriers in diamond was studied computationally and the results agree very well with experiments.

\section{Future Work}

Futher experimental and computational efforts will investigate the influence of contact behavior and charge injection on dark current, switch performance and recovery. Continued steady state and transient analysis modeling of charge transport in diamond will provide a better understanding of the physics leading to optimization of switch performance.

\section{References}

[1] L.S. Pan, S. Han, D.R. Kania, "Electronic Properties of Diamond" Diamond Films and Technology, 1992, Vol.2, pp 99-154

[2] W.W. Hofer, K.H. Schoenbach, R.P. Joshi, "High Average Power Switching in Diamond", Conference Record 1992, Twentieth Power Modular Symposium, Myrtle Beach, SC, pg. 241

[3] R. Beach, B. Benett, et al., "Modular Microchannel Cooled Heatsinks for High Average Power Laser Diode Arrays", UCRL-JC-106942 (LLNL internal report), June 1991

[4] R.P. Joshi, K.H. Schoenbach, C. Molina, W.W. Hofer, "Studies of Electron Beam Penetration and Free Carrier Generation in Diamond Films", to appear in the August 1993 issue of J. Appl. Phys. 


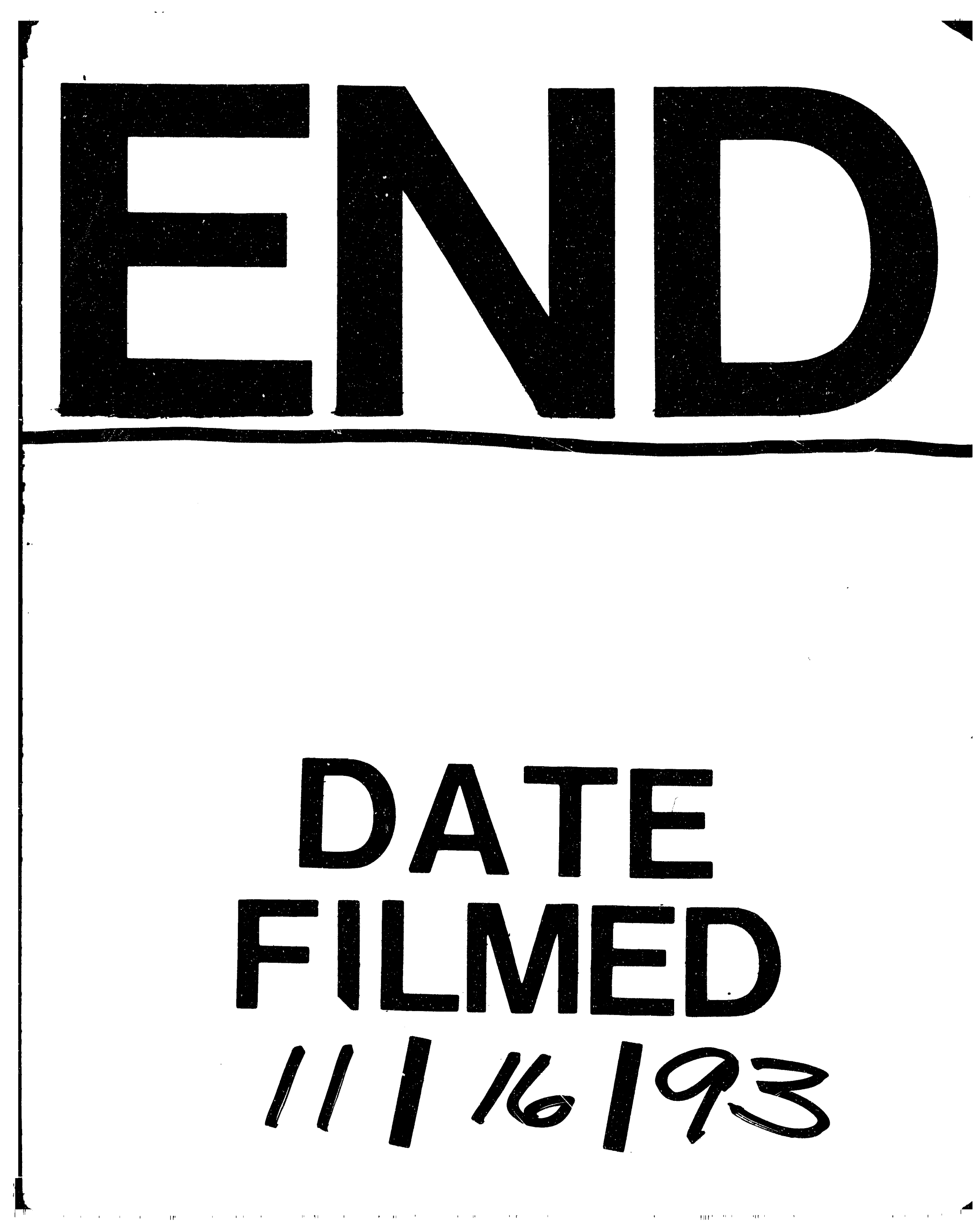


